\title{
KOMBINASI SISTEM BERBASIS WEB DAN ANDROID SEBAGAI APLIKASI PRESENSI KEGIATAN MENGGUNAKAN $Q R$ CODE
}

\author{
Riovan Styx Roring1, FX Nanang Sujatmiko² \\ Dosen Universitas Mulia ${ }^{1,2}$ \\ Jalan ZA Maulani No. 9 Damai Bahagia, Balikpapan, Kalimantan Timur, \\ Indonesia ${ }^{1,2}$ \\ Sur-el : riovan@universitasmulia.ac.id ${ }^{1}$, fx.nanang@universitasmulia.ac.id²
}

\begin{abstract}
Registration and list of attendees are an important factor to be done in formal and informal activities. The purpose is to know the attendees' personal data and presence. Registration and presence using the manual method such as form filling in a piece of paper produce problem, among them is over excess of paper and time consuming presence activity. Therefore, a new efficient and effective system that take advantage of Android Smartphone and Quick Response Code (QR Code) as Smart Attendance System is needed. The use of Android and QR Code technology simplify registration and presence process so that the proses would be much faster and efficient. The design of QR Code presence application based on Android is using System Development Life Cycle (SDLC) Waterfall model and designed using Use Case Diagram and Entity Relationship Diagram. The presence application is made using combination of two platform, that is Android and web. On the Android Smartphone there are scanner and administrator profile. Whilst at the web platform contain participant, event, and admin database. The existence of the design and Smart Attendance system implementation, registration and list of attendees process will be faster, efficient, and used as on of the smart system to support the smart city is expected.
\end{abstract}

Keywords: Quick Response Code, Smart Attendance, Smart City, SDLC.

\begin{abstract}
Abstrak : Registrasi dan daftar hadir peserta merupakan faktor penting yang harus dilakukan dalam berbagai kegiatan formal maupun non formal. Tujuannya untuk mengetahui data diri peserta dan kehadiran peserta. Registrasi dan presensi yang menggunakan cara manual yaitu dengan mengisi form pada selembar kertas menimbulkan kendala, diantaranya penggunaan kertas yang berlebihan dan waktu yang cukup lama untuk presensi. Untuk itu, perlu adanya sistem baru yang lebih efisien dan efektif yaitu memanfaatkan smartphone android dan teknologi Quick Response Code (QR Code) sebagai sistem Smart Attendance. Pemanfaatan teknologi android dan QR Code akan memudahkan proses registrasi dan presensi sehingga proses lebih cepat dan efisien. Perancangan aplikasi presensi menggunakan QR Code berbasis android ini menggunakan metode System Development Life Cycle (SDLC) model Waterfall, dengan desain pemrograman Use Case Diagram dan Entity Relationship Diagram. Aplikasi presensi ini dibuat menggunakan kombinasi dua platform yaitu android dan web. Pada smartphone android terdapat scanner dan profile pengelola/admin. Sedangkan pada platform web berisi database peserta, event, dan admin. Diharapkan dengan adanya perancangan dan implementasi sistem Smart Attendance ini, proses registrasi dan daftar hadir lebih cepat, efisien dan dapat digunakan sebagai salah satu sistem cerdas menuju pendukung Smart City
\end{abstract}

Kata kunci: Quick Response Code, Smart Attendance, Smart City, SDLC.

\section{PENDAHULUAN}

Registrasi dan pencatatan kehadiran (presensi) peserta merupakan faktor penting yang harus dilakukan dalam melaksanakan setiap kegiatan. Registrasi dan presensi bertujuan untuk mengetahui data diri peserta dan hadir tidaknya peserta tersebut dalam suatu kegiatan. Registrasi dan presensi peserta biasanya masih menggunakan cara manual, yaitu dengan 
mengisi form dan tanda tangan pada selembar kertas. Sistem lama ini yang sering digunakan ini dapat menimbulkan beberapa kendala diantaranya penggunaan kertas yang berlebihan dan waktu yang cukup lama untuk registrasi, terutama pada saat peserta melakukan registrasi ulang dan pembagian atribut peserta, panitia harus melakukan validasi data dengan jumlah peserta yang tidak sedikit. Dengan penggunaan kertas, data tiap peserta dapat lebih mudah tercecer sehingga beresiko untuk melakukan pendataan ulang.

Berdasarkan permasalahan di atas, dibutuhkan sebuah sistem baru yang lebih efisien dan efektif, yang bisa terintegrasi satu sama lain sehingga registrasi dan presensi dapat dilakukan dengan cepat dan akurat. Ide yang muncul adalah memanfaatkan smartphone android dan Quick Response Code atau QR Code dalam sistem Smart Attendance yang dapat diimplementasikan sebagai pendukung Smart City. Smartphone merupakan ponsel multimedia yang menggabungkan fungsionalitas PC dan handset sehingga menghasilkan gadget yang mewah, dimana terdapat kamera, video, pesan teks, pemutar musik, akses email, fitur GPS, game, pengelola informasi pribadi, jasa telepon internet dan bahkan terdapat telepon yang juga berfungsi sebagai kartu kredit [1]. Dengan fitur kamera pada smartphone, gambar yang berupa QR Code dapat diambil dan disimpan serta ditampilkan. Pemanfaatan QR Code dapat memudahkan proses pengolahan informasi data peserta kegiatan dan pengambilan data peserta tanpa perlu melakukan input kembali.

Berdasarkan latar belakang masalah di atas, maka permasalahan yang akan dibahas dalam penelitian ini adalah sebagai meliputi: rancangang sistem Smart Attendance menggunakan QR Code berbasis android untuk mendukung kebutuhan Smart City dan sistem presensi yang saling terintegrasi agar dapat diakses di tempat yang berbeda dalam waktu yang bersamaan

Batasan masalah pun juga dibahas pada penelitian ini. Aplikasi presensi hanya untuk peserta dan pengelola/admin sistem pendukung Smart City, dan hanya difokuskan pada registrasi dan presensi peserta.

1. Sistem presensi hanya diaktifkan ketika kegiatan sedang berlangsung.

2. Aplikasi dibuat menggunakan platform android dan web.

Untuk mengetahui dan memahami proses perancangan sistem presensi menggunakan $\mathrm{QR}$ Code berbasis android. Dengan merancang sistem presensi yang saling terintegrasi satu sama lain. Setelah merancang sistem, registrasi dan presensi admin maupun peserta, menjadi lebih cepat dan optimal.

Manfaat yang dapat diperoleh dalam penelitian ini yaitu Sebagai salah satu sistem pendukung dalam Smart City. Mempermudah dan mempercepat proses registrasi dan presensi serta rekapitulasi data peserta. Lalu dapat memberikan informasi data peserta yang valid. Dan menghemat penggunaan kertas dan waktu dalam pencatatan presensi peserta.

\section{METODOLOGI PENELITIAN}

Penelitian ini dilakukan dengan pendekatan kualitatif, dimana peneliti mencoba untuk mengumpulkan data-data yang akan 
digunakan dalam suatu proses perhitungan yang menghasilkan sistem Smart Attendance untuk mendukung Smart City. Fokus penelitian ini untuk memastikan data sesuai dengan fakta yang ada dilapangan dan merancang sistem sesuai dengan data-data yang dikumpulkan.

\subsection{Metode pengembangan Sistem}

Metode penelitian pada sistem aplikasi presensi ini menggunakan metode System Development Life Cycle (SDLC). SDLC adalah metode pengembangan sistem tradisional yang digunakan sebagian besar organisasi saat ini. SDLC adalah kerangka kerja (framework) yang terstruktur yang berisi proses-proses sekuensial dimana sistem informasi dikembangkan [2].

Tahapan pada metode System Development Life-cycle (SDLC) yang menggunakan 6 aspek utama sebagai alur pengembangan perangkat lunak. Keenam aspek utama disajikan pada gambar 1[3].

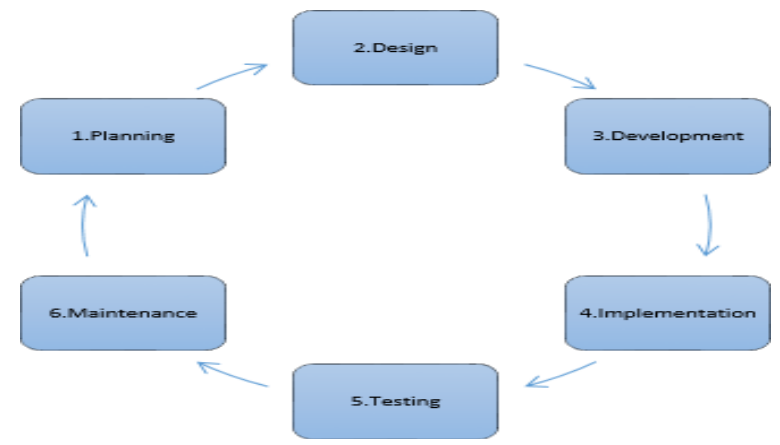

Gambar 1. System Development Life Cycle (SDLC)

\subsection{Metode Pengumpulan Data}

Persiapan awal dalam pengembangan sistem adalah dengan mempersiapkan rencana pengumpulan data. Data merupakan bagian terpenting dalam sebuah penelitian. Selain itu pencatatan daftar kebutuhan dari perangkat lunak, perangkat keras, administrasi, dan kebutuhan lainnya juga penting dalam penelitian ini. Perencanaan juga akan melalui proses evaluasi dimana setiap task akan diberikan nilai kebutuhan.

Pengumpulan data pada penilitian ini menggunakan metode Wawancara dan metode Studi Literatur. 1) Metode wawancara merupakan teknik pengumpulan data yang dilakukan melalui tatap muka dan tanya jawab langsung antara pengumpul data terhadap narasumber / sumber data. 2) Studi literatur merupakan salah satu metode pengumpulan data untuk mendapatkan data-data yang sifatnya teoritis yaitu dengan cara membaca literatur yang relevan dengan pengamatan yang penulis lakukan.

\subsection{Metode Pengolahan Data}

Pengolahan data dibagi dalam 3 langkah yaitu data reduction, data display, dan conclusion drawing and verification[4]. Tahap pertama dilakukan dengan melakukan penentuan dan memfokuskan data kepada data kuisoner yang dapat digunakan sebagai data yang nantinya dapat disajikan dengan menghilangkan data-data yang tidak valid.

Penyajian data dilakukan dengan menarik variabel-variabel yang telah didapat kemudian diisi dengan sampel-sampel sesuai dengan kebutuhan dan dimensi dari variabel tersebut. Tabel kemudian diisi dengan sampel-sampel sesuai dengan kebutuhan dan dimensi dari variabel tersebut.

Tahap terakhir dilakukan dengan menarik kesimpulan berdasarkan fenomena-fenomena yang didapatkan dari lingkungan penelitian dan 
menggabungkannya dengan data observasi yang ada. Verifikasi dapat dilakukan bersamaan dengan pelaksanaan ujicoba dengan menambahkan daftar kebutuhan dalam ujicoba tersebut.

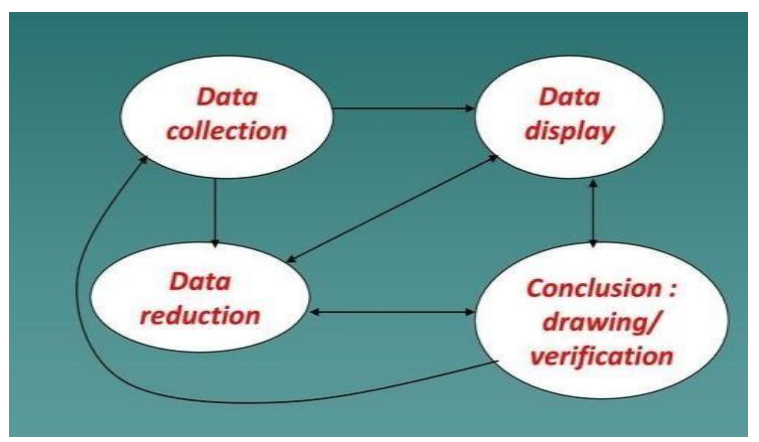

Gambar 2. Proses Pengolahan Data

\subsection{Metode Pengembangan Perangkat Lunak}

Metode pengembangan perangkat lunak yang dipakai dalam penelitian ini adalah Software Development Life Cycle (SDLC) model Waterfall. Model Waterfall melakukan pendekatan secara sistematis dan urut mulai dari level kebutuhan sistem lalu menuju ke tahap analisis, desain, coding, testing/verification, dan maintenance [5].

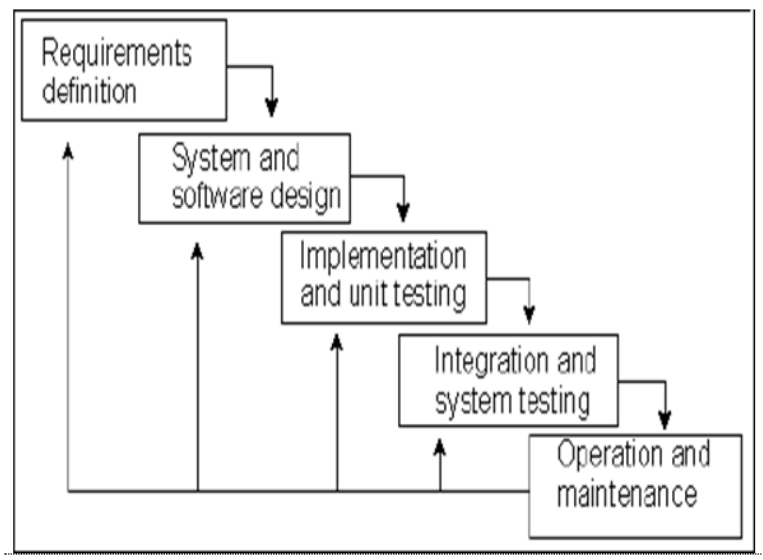

Gambar 3. Model Waterfall

\subsection{Metode Pengujian}

Metode pengujian yang digunakan pada penelitian ini yaitu dengan menggunakan pengujian kotak hitam (Black Box Testing). Black Box Testing adalah pengujian yang dilakukan hanya mengamati hasil eksekusi melalui data uji dan memeriksa fungsional dari perangkat lunak[6].

Tabel 1. Contoh Pengujian Black Box

\begin{tabular}{|c|c|c|c|c|}
\hline No & $\begin{array}{l}\text { Halaman } \\
\text { Yang diuji }\end{array}$ & Aksi Aktor & $\begin{array}{l}\text { Reaksi } \\
\text { Sistem }\end{array}$ & $\begin{array}{c}\text { Hasil } \\
\text { (Sesuai/ } \\
\text { Tidak } \\
\text { Sesuai) }\end{array}$ \\
\hline 1 & $\begin{array}{c}\text { Halaman } \\
\text { Awal } \\
\text { Admin }\end{array}$ & $\begin{array}{l}\text { Pilh Menu } \\
\text { Login }\end{array}$ & $\begin{array}{c}\text { Masuk } \\
\text { Halaman } \\
\text { Login }\end{array}$ & \\
\hline 2 & $\begin{array}{l}\text { Login } \\
\text { Admin }\end{array}$ & $\begin{array}{l}\text { Memasukkan } \\
\text { Username } \\
\text { dan } \\
\text { Password }\end{array}$ & $\begin{array}{l}\text { Masuk } \\
\text { ke } \\
\text { Halaman } \\
\text { Utama } \\
\text { Website }\end{array}$ & \\
\hline
\end{tabular}

\section{HASIL DAN PEMBAHASAN}

\subsection{Perancangan Sistem.}

Perancangan Sistem merupakan langkah awal yang dilakukan sebelum membangun sebuah sistem berbasis Komputer[7]. Setelah diketahui kebutuhan akan sistem yang akan dibangun melalui tahapan pengumpulan data, maka langkah selanjutnya adalah membuat presensi kegiatan menggunakan $Q R$ Code (rancangan sistem yang akan dibangun tersebut. Rancangan sistem yang dihasilkan akan menjadi gambaran proses yang terjadi dalam sistem yang aan dibangun nantinya. Tahapan perancangan sistem menjadi bagian terpenting dalam membangun atau mengembangkan sebuah sistem atau aplikasi berbasis komputer, karena dalam tahapan ini juga akan dapat dispesifikasikan aspek aspek kebutuhan dari sistem yang akan dibangun baik hardware maupun softwarenya [8]. Rancangan Sistem untuk membangun presensi kegiatan 
menggunakan $Q R$ Code ini dibuat dengan menggunakan tools Diagram Unified Modelling Language (UML).

Selain itu, pengguna dapat melihat informasi lengkap setiap order, rating, dan kelengkapan dokumen-dokumennya beserta status approvalnya melalui aplikasi ini. Sedangkan informasi dalam map disajikan sama seperti informasi di aplikasi pelanggan.

\section{a) Use Case Diagram}

Diagram use case mendeskripsikan untuk mengetahui fungsi apa saja yang ada di dalam sebuah sistem dan siapa saja yang berhak menggunakan fungsi - fungsi tersebut [9].
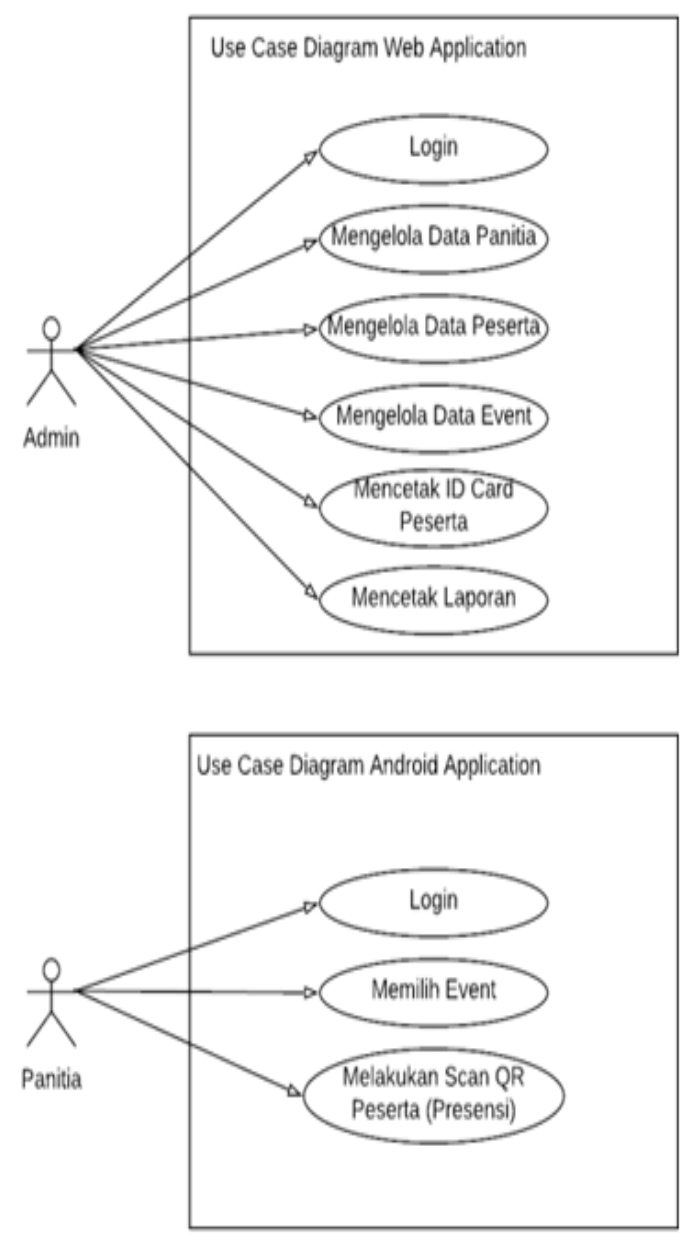

Gambar 4. Use Case Diagram Aplikasi

\section{Presensi}

\section{b) Entity Relationship Diagram}

Pada sistem aplikasi presensi terdapat 7 entitas yaitu, Users, Member, Events, Subevent, Present, Present_detail, dan Sessions. Setiap entitas memiliki atributnya masing-masing dan saling terhubung antara satu entitas ke entitas yang lain.

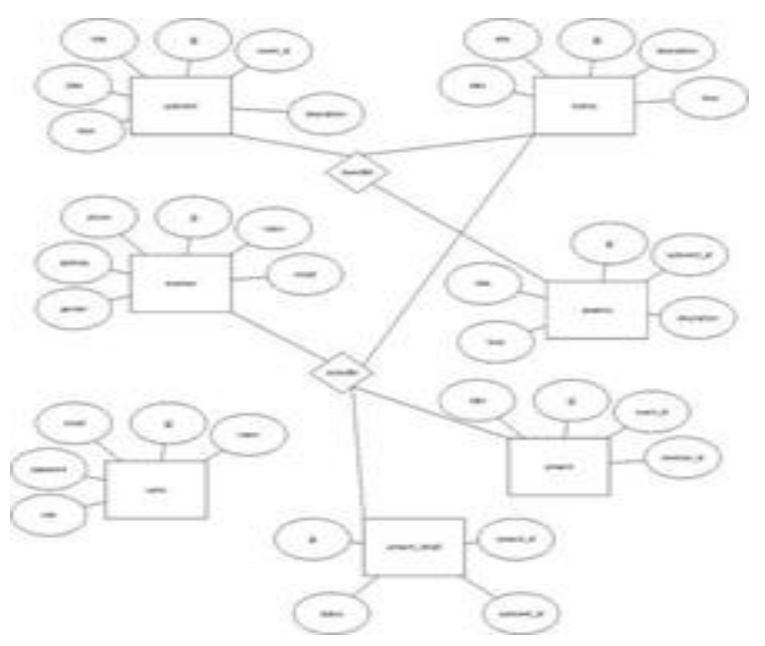

Gambar 5. Entity Relationship Diagram

Aplikasi Presensi

\section{c) Database}

Database pada sistem aplikasi presensi, tabel yang dibuat berjumlah 9 tabel yaitu, tabel events, tabel members, tabel migrations, tabel password_resets, tabel presentdetails, tabel presents, tabel sessions, tabel subevents, dan tabel users.

Tabel 2. Tabel Events

\begin{tabular}{|c|c|c|c|}
\hline Nama Field & Tipe Data & Panjang & Ket \\
\hline id & int & 10 & $\begin{array}{c}\text { Primary } \\
\text { key }\end{array}$ \\
\hline $\begin{array}{l}\text { title } \\
\text { date }\end{array}$ & $\begin{array}{l}\text { varchar } \\
\text { date }\end{array}$ & 255 & \\
\hline $\begin{array}{c}\text { time } \\
\text { description }\end{array}$ & $\begin{array}{l}\text { varchar } \\
\text { text }\end{array}$ & 255 & \\
\hline $\begin{array}{l}\text { file } \\
\text { created at } \\
\text { update at }\end{array}$ & $\begin{array}{l}\text { varchar } \\
\text { timestamp } \\
\text { timestamp }\end{array}$ & 255 & \\
\hline
\end{tabular}


Tabel 3. Tabel Members

\begin{tabular}{cccc}
\hline Nama Field & Tipe Data & Panjang & Ket \\
\hline id & int & 10 & $\begin{array}{c}\text { Primary } \\
\text { key }\end{array}$ \\
name & varchar & 255 & \\
address & varchar & 255 & \\
phone & varchar & 255 & \\
gender & varchar & 255 & \\
email & varchar & 255 & \\
created at & timestamp & & \\
update at & timestamp & & \\
\hline
\end{tabular}

Tabel 4. Tabel Migrations

\begin{tabular}{llll}
\hline Nama Field & Tipe Data & Panjang & Ket \\
\hline id & int & 10 & $\begin{array}{l}\text { Primary } \\
\text { key }\end{array}$ \\
$\begin{array}{lll}\text { migration } \\
\text { batch }\end{array}$ & $\begin{array}{l}\text { varchar } \\
\text { int }\end{array}$ & 255 & \\
\hline
\end{tabular}

Tabel 5. Tabel Present

\begin{tabular}{cccc}
\hline Nama Field & Tipe Data & Panjang & Ket \\
\hline id & int & 10 & $\begin{array}{c}\text { Primary } \\
\text { key }\end{array}$ \\
present id & Int & 11 & \\
subevent id & Int & 11 & \\
Status & Int & 11 & \\
created at & timestamp & & \\
update at & timestamp & & \\
\hline
\end{tabular}

Tabel 6. Tabel User

\begin{tabular}{cccc}
\hline Nama Field & Tipe Data & Panjang & Ket \\
\hline id & int & 10 & $\begin{array}{c}\text { Primary } \\
\text { key }\end{array}$ \\
name & varchar & 255 & \\
email & varchar & 255 & $\begin{array}{c}\text { Unique } \\
\text { key }\end{array}$ \\
& & & \\
password & varchar & 255 & \\
role & varchar & 255 & \\
remember & varchar & 100 & \\
token & & & \\
created at & timestamp & & \\
update at & timestamp & & \\
\hline
\end{tabular}

\subsection{User interface}

User Interface merupakan penggambaran tampilan (interface) sebuah sistem yang akan digunakan secara langsung oleh pengguna, dan juga merupakan penggambaran interaksi yang dapat dilakukan oleh pengguna dan sistem [10]. Dalam tahapan ini, rancangan aplikasi menggunakan prinsip User Centered Design sebagai landasan perancangan tampilan. User Centered Design dapat digunakan sebagai salah satu pendekatan pemilihan operasional yang dimiliki pengguna dalam mengoperasikan sistem [11].

\section{A. Menu Administrator}

Pada gambar 6,7,8, dan 9 menampilkan tampilan pada menu Admin, gambar 6 login berfungsi sebagai security karena hanya admin yang berhak masuk ke dalam sistem. Pada halaman ini admin harus mengisi username dan password agar dapat masuk ke menu utama. Gambar 7 berisi form Resume yang menampilkan event dan jumlah peserta yang mengikuti event tersebut juga terdapat diagram untuk menampilkan presentasi event yang diminati. Gambar 9 berisi List Event, Hari, Tanggal, dan Waktu. Admin dapat melihat detail event, menambah, mengedit, dan menghapus.

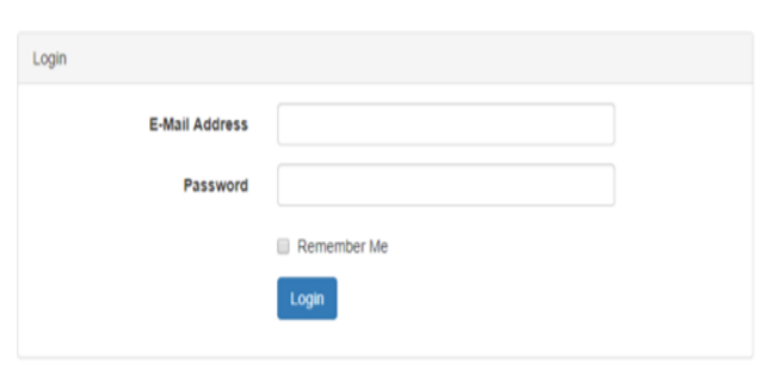

Gambar 6. Halaman Login Admin

Gambar 7. Halaman Home Admin 


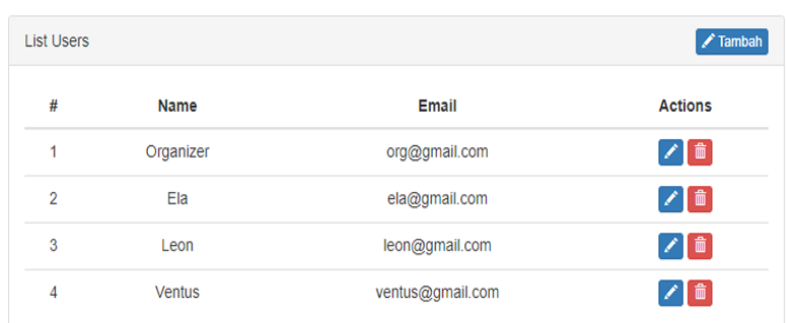

\section{Gambar 8. Halaman Users Admin}

\section{B. Menu Event}

Pada menu ini admin dan user bisa mengakses halaman ini. List Event, Hari, Tanggal, dan Waktu ditampilkan pada halaman ini. Admin dapat melihat detail event, menambah, mengedit, dan menghapus.

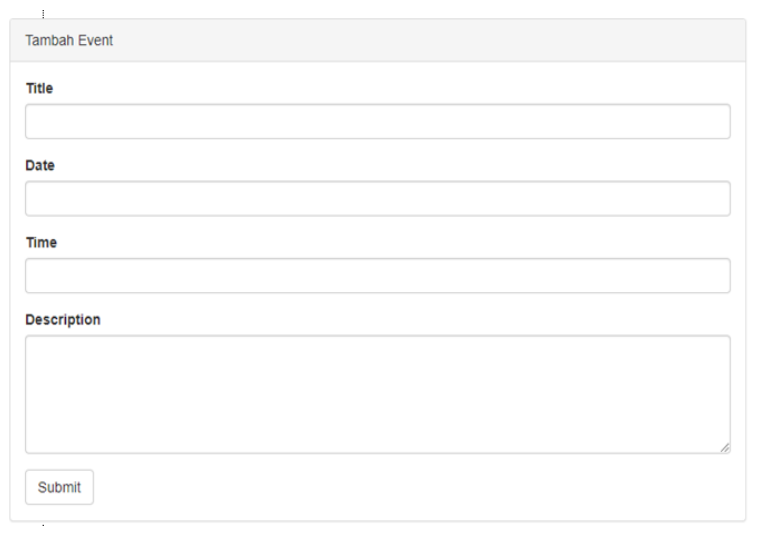

Gambar 9. Halaman Tambah Event

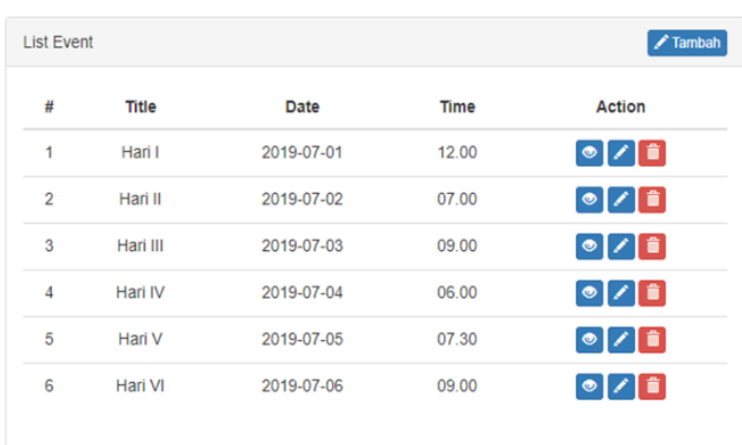

Gambar 10. Halaman Event Admin

\section{Menu User}

Menu User adalah bagian dari antarmuka yang digunakan oleh user (pengguna) agar berinteraksi dengan sistem. Pada bagian menu ini, pengguna dapat menggunakan aplikasi untuk memudahkan presensi kehadiran event menggunakan aplikasi presensi kegiatan menggunakan $Q R$ Code. Menu pada pengguna dapat diakses melalui web dan smartphone berbasis android

Pada gambar 11 disajikan Halaman ID Card Peserta yang terdapat QR Code dan bisa di print. Pada halaman ini terdapat keterangan Nama, Waktu, Alamat, No.HP, dan email peserta.

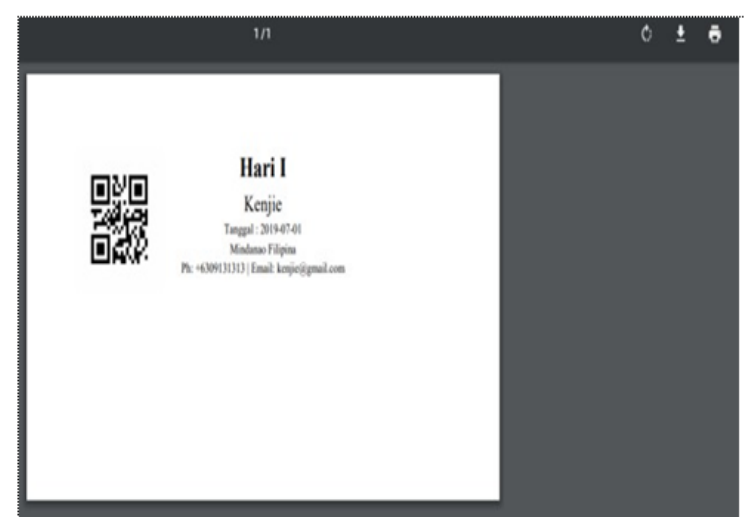

\section{Gambar 11. Halaman ID Card Peserta}

Pada gambar 12,13, dan 14 Halaman ini diakses oleh panitia event untuk mengakses, menge-scan QR Code pada ID Card peserta (melakukan presensi) sehingga panitia dapat mengetahui kehadiran peserta tersebut. Panitia harus menginput email dan password agar dapat masuk ke menu selanjutnya.

Dihalaman ini juga panitia dapat mengetahui Nama dan Email Panitia yang sedang Login. Setelah Login, panitia harus menginput email dan password agar dapat masuk ke menu selanjutnya. 
Email

Password

\section{SUBMIT}

Gambar 12. Halaman Login Panitia

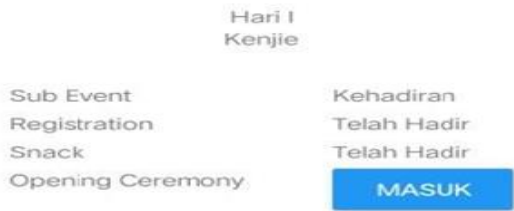

Gambar 13. Halaman Scanner Panitia

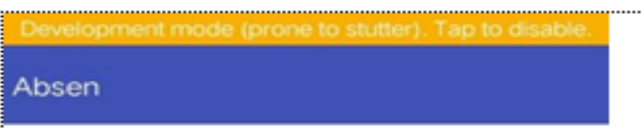

Name

Administrator

Email

hello@gmail.com

Password

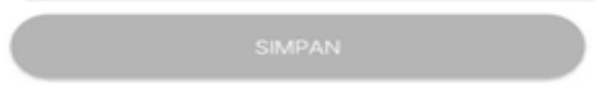

\section{Scanner}

\section{Profile}

\section{Gambar 14. Halaman Profile Panitia}

Berikut adalah Halaman Kehadiran, yang muncul setelah Panitia melakukan scanning pada ID Card peserta. Pada halaman ini terdapat sub- event dalam 1 hari dan panitia dapat meng-klik button 'Masuk' untuk mengisi kehadiran peserta dalam sub-event tersebut.
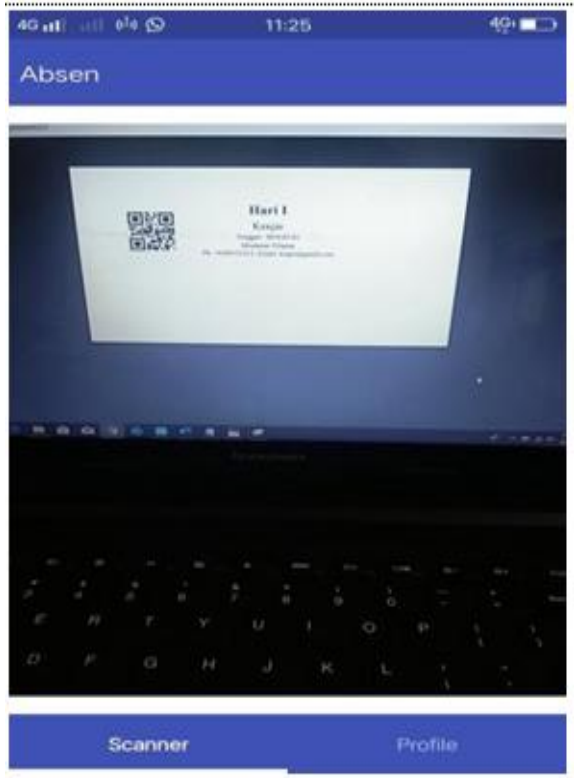

\section{Gambar 15. Halaman Kehadiran}

\subsection{Pengujian Sistem}

Pengujian sistem dilakukan untuk mengetahui apakah sistem yang dirancang lalu di implementasikan telah berjalan dengan baik sesuai dengan rencana yang sudah dirancang sebelumnya atau tidak. Untuk melakukan pengujian sistem digunakan metode Black Box.

Tabel 10. Pengujian Sistem menggunakan Black Box

\begin{tabular}{|c|c|c|c|c|}
\hline$N O$ & $\begin{array}{l}\text { Halaman } \\
\text { yang diuji }\end{array}$ & $\begin{array}{l}\text { Aksi } \\
\text { Aktor }\end{array}$ & $\begin{array}{l}\text { Reaksi } \\
\text { Sistem }\end{array}$ & $\begin{array}{c}\text { Hasil } \\
\text { (Sesuai/ } \\
\text { Tidak } \\
\text { Sesuai) }\end{array}$ \\
\hline 1 & $\begin{array}{l}\text { Halaman } \\
\text { Login } \\
\text { Web }\end{array}$ & $\begin{array}{c}\text { Input } \\
\text { email dan } \\
\text { Password }\end{array}$ & $\begin{array}{c}\text { Form terisi } \\
\text { data sesuai } \\
\text { input }\end{array}$ & Sesuai \\
\hline 2 & $\begin{array}{l}\text { Halaman } \\
\text { Login } \\
\text { Web }\end{array}$ & $\begin{array}{c}\text { Klik } \\
\text { Login }\end{array}$ & $\begin{array}{c}\text { Menampilka } \\
\text { n Halaman } \\
\text { Utama }\end{array}$ & Sesuai \\
\hline 3 & $\begin{array}{l}\text { Halaman } \\
\text { Home } \\
\text { Web }\end{array}$ & $\begin{array}{l}\text { Klik } \\
\text { Home }\end{array}$ & $\begin{array}{c}\text { Menampilka } \\
\text { n form } \\
\text { resume, } \\
\text { menampilka } \\
\text { n persentase } \\
\text { sesuai data } \\
\text { event }\end{array}$ & Sesuai \\
\hline
\end{tabular}




\begin{tabular}{|c|c|c|c|c|}
\hline 4 & $\begin{array}{c}\text { Halaman } \\
\text { Home } \\
\text { Web }\end{array}$ & $\begin{array}{c}\text { Klik } \\
\text { Details }\end{array}$ & $\begin{array}{c}\text { Menampilka } \\
\text { n Halaman } \\
\text { Resume }\end{array}$ & Sesuai \\
\hline 5 & $\begin{array}{c}\text { Halaman } \\
\text { Resume }\end{array}$ & $\begin{array}{c}\text { Klik } \\
\text { Details }\end{array}$ & $\begin{array}{l}\text { Menampilka } \\
\text { n Nama } \\
\text { yang hadir } \\
\text { dan tidak } \\
\text { hadir }\end{array}$ & Sesuai \\
\hline 6 & $\begin{array}{c}\text { Halaman } \\
\text { Resume }\end{array}$ & Klik Print & $\begin{array}{c}\text { Menampilka } \\
\text { n Halaman } \\
\text { Print }\end{array}$ & Sesuai \\
\hline 7 & $\begin{array}{c}\text { Halaman } \\
\text { Event }\end{array}$ & $\begin{array}{c}\text { Klik } \\
\text { Tambah }\end{array}$ & $\begin{array}{c}\text { Menampilka } \\
\text { n Form } \\
\text { Tambah } \\
\text { Event }\end{array}$ & Sesuai \\
\hline 8 & $\begin{array}{c}\text { Halaman } \\
\text { Tambah } \\
\text { Event }\end{array}$ & $\begin{array}{c}\text { Input } \\
\text { Title, } \\
\text { Date, } \\
\text { time, } \\
\text { Descriptio } \\
\text { n }\end{array}$ & $\begin{array}{l}\text { Form terisi } \\
\text { data sesuai } \\
\text { input }\end{array}$ & Sesuai \\
\hline 9 & $\begin{array}{c}\text { Halaman } \\
\text { Tambah } \\
\text { event }\end{array}$ & $\begin{array}{c}\text { Klik } \\
\text { Submit }\end{array}$ & $\begin{array}{c}\text { Data } \\
\text { tersimpan } \\
\text { dan list } \\
\text { event }\end{array}$ & Sesuai \\
\hline
\end{tabular}

\section{KESIMPULAN}

Berdasarkan uraian dari hasil penelitian ini menghasilkan aplikasi presensi kegiatan menggunakan qr code. Aplikasi ini dapat digunakan panitia untuk presensi peserta pada kegiatan atau event-event dengan mudah. Juga dengan menggunakan media kamera handphone yang bisa membaca $Q R$ Code, presensi menjadi lebih cepat dan optimal. Sistem baru ini juga sangat memudahkan, karena registrasi dan presensi tidak lagi menggunakan cara manual dengan mengisi form pada selembar kertas sehingga dapat menghemat penggunaan kertas dan waktu. Penggunaan aplikasi presensi ini sebagai aplikasi penunjang smart city dalam kegiatan-kegiatan dalam ruang lingkup kota juga dapat mendorong pemanfaatan dan perkembangan kota menjadi lebih baik.

\section{UCAPAN TERIMA KASIH}

Direktorat Riset dan Pengabdian Masyarakat Direktorat Jenderal Penguatan Riset dan Pengembangan Kementerian Riset dan Teknologi/ Badan Riset dan Inovasi Nasional sesuai dengan Kontrak Penelitian Dosen Pemula Tahun 2020.

\section{DAFTAR PUSTAKA}

[1] Yudhanto,Y.; Wijayanto,A., 2017, Mudah Membuat dan Berbisnis Aplikasi Android dengan Android Studio, PT Elex Media Komputindo, Jakarta.

[2] Roring, Riovan Styx, and Kusrini Kusrini. "Integrasi Sistem berbasis Predictive Analytics untuk Pasar Tradisional Indonesia." CSRID (Computer Science Research and Its Development Journal) 9.1 (2017): 21-30.

[3] Ragunath, P. K., et al. "Evolving a new model (SDLC Model-2010) for software development life cycle (SDLC)." International Journal of Computer Science and Network Security 10.1 (2010): 112-119.

[4] Roring, Riovan Styx, and Muhammad Nurfalah Setiawan. "SISTEM BIMBINGAN PENJUALAN "JUTUNG" UNTUK USAHA MIKRO DAN KECIL." SEMINASTIKA 1.1 (2018): 113122.

[5] Nugraha, Wahyu, Muhamad Syarif, and Weiskhy Steven Dharmawan. "Penerapan Metode SDLC Waterfall dalam Sistem Informasi Inventori Barang Berbasis Desktop." JUSIM (Jurnal Sistem Informasi Musirawas) 3.01 (2018): 2329.

[6] Jacob, Pramod Mathew, and M. Prasanna. "A Comparative analysis on Black box testing strategies." 2016 International Conference on Information Science (ICIS). IEEE, 2016.

[7] Roring, Riovan Styx, and Rizal Baday. "Perancangan Aplikasi Penggajian Karyawan Tetap pada PT. Rachmat Cahaya Abadi." METIK JURNAL 1.1 (2017): 6-13. 
[8] Roring, Riovan Styx. "INSTRUMEN PENILAIAN DOSEN SEBAGAI KNOWLEDGE MANAGEMENT SYSTEM DALAM LINGKUNGAN INTERNAL KAMPUS." METIK JURNAL 2.1 (2018): 7074.

[9] Fauzan, Reza, et al. "Use Case Diagram Similarity Measurement: A New Approach." 2019 12th International Conference on Information \& Communication Technology and System (ICTS). IEEE, 2019.

[10] Shneiderman, Ben, et al. Designing the user interface: strategies for effective human-computer interaction. Pearson, 2016.

[11] Graham, Andrea K., et al. "User-centered design for technology-enabled services for eating disorders." International Journal of Eating Disorders 52.10 (2019): 10951107 